had hitherto, he pointed out, been limited to the fundamental standards of mass and length and questions intimately connected with these. M. Battistella urged that this was insufficient to secure uniformity in all the details of importance to international science. In the name of his Government he directed attention to (I) the necessity for a legal definition, not only of the fundamental units of mass and length, but also of a whole series of connected units-units dealt with in the study of light, heat, engincering, and electrical problems, and others, as well as for the specification of the instruments best suited for the measurement of these quantities; and (2) the importance of the standardisation of the types of instruments to be employed so as to secure uniformity among countries using the metric system. As a result the International Committee was entrusted with the mandate of examining the proposal of the Italian delegate with the view of securing agreement on the questions raised.

Enough has, perhaps, been written to show that the matters under discussion were of no small importance. None of them were settled; it remains for a future conference to examine them afresh and to decide each in the manner which promises best to be of service to the world and to turn to advantage the lessons of the past five years of trial.

And now there is no space to describe the other half of the volume: M. Pérard's elaborate note on the reduction of certain classes of observation or 11. Chappuis's two papers on the determination of the boiling-point of sulphur and the coefficient of dilatation of mercury. It must suffice to mention the results. For the boiling-point of sulphur on the thermodynamic scale under normal pressure he finds the value $444.60^{\circ}$. Holborn and Henning give $444.51^{\circ}$, and Day and Sosman $444.55^{\circ}$. The value at present in use at the National Physical Laboratory is $447.5^{\circ}$.

For the coefficient of dilatation of mercury his value is $0.18162884 \times 10^{-3}+\$ .5962282 \times 10^{-9} \mathrm{~T}$. This value does not differ greatly from that deduced from his own earlier experiments of 1890 ; the differences between these results and those of Callendar and Moss (Phil. Trans., IgII) are considerably greater. For the range from $60^{\circ}$ to $100^{\circ}$, whire Chappuis's two results agree very closely, the difference between them and the figures of Callendar and Moss would correspond with a temperature error of $0.25^{\circ}$, an error ten times greater than that which M. Chappuis considers possible.

11. Chappuis died as the proofs of his paper were passings through the press. Those who know his work will wish to join in M. Guillaume's tribute to his memorv. He writes:- "These two determinations of the coefficient of dilatation of mercury, separated by a quarter of a century, carried out by methods entirely different and with instruments which had no part in common, and yet in close agrement, will remain for metrologists of the future among the finest examples of the work of an experimenter gifted with consummate skill, with a devotion to his task which stood every test and with an intense desire to reach the truth." R. T. G.

\section{SOME INDIAN SUGAR-CANES AND THEIR ORIGIN.}

DR. C. A. BARBER, Government Sugar-Cane Expert, Madras, continuing his studies on classification of two new groups which he describes as Saretha and Sunnabile (Memoirs of the Depart- ment of Agriculture in India, Botanical Series ix., No, 4). In the course of study of the. Indian canes a sharp distinction was observed between two classes. There was, on one hand, a large series of thick, juicy canes commonly grown on a crop-scale in the more tropical parts, or in the northern parts usually in small plots under high cultivation near large towns, in which they were used for eating as fruit. A second series of thin, hardy canes, grown under field conditions all over India, especially in the north, were unfitted for chewing, but were crushed and made into "jaggery" or "gur." It is this second series which includes the subject of the memoir. In contrast with the first series these thin canes are considered to be indigenous to India, and were found to include several well-defined classes. A number of apparently isolated forms from all parts of the country were at first difficult of arrangement, but were afterwards found to fall into two groups, characterised by bending or erect leaf-tips and presence or absence of circlets of hairs at the nodes; the canes known as Saretha and Sunnabile have been selected to give names to the new groups. In classifying varieties under these two groups the characters usually employed in systematic work, such as differences in the floral organs and size of organs and plants, have not been found helpful, but clependence has been placed on a series of minute local differences. Thus in all the Saretha group there is a minute incrustation on the rind, as if it had been attacked by a small mite, whereas this is absent in the Sunnabile group. The density of blom is greater in the Saretha group, but the blackening of this bloom by fungus is sharper and more circumscribed in the Sunnabile sroup. Thickness of stem and size and vigour of plant seem to be of no value; and the existence of insignificant characters in canes differing considerably in external appearance, and extending through wide stretches of country under varying climatic and cultural conditions, adds to their importance. Some sixty to seventy such characters are dealt with in detail.

Dr. Barber further points out that his classification is not merely an empirical statement of unconnected differences, a sort of analytical key for the separation of varicties, but also presents data for a statement on the lines of evolution among a section of cultivated canes. He claims to have advanced towards solving the origin of cultivated canes from their wild ancestor, and to have established a series of connecting links between cultivated canes and the wild species of Saccharum now growing in India. A wide collection of specimens shows that there are some very distinct varieties of Saccharum spontaneum more or less confined to definite geographical regions. A development in the size of the vegetative organs is observed in passing from the dry to the humid tracts in India similar to that met with in the Saretha and Sunnabile series of sugar-canes, and in the detailed list of characters showing differences between the two groups we find a number mentioned in which the Saretha group approaches S. spontaneum. Such are the black incrustation on the stem, the circlet of hairs on the nodes, and certain leaf-characters, and these resemblances suggest that the Saretha groun is the more primitive. But as a study of the seedlings of $S$. spontaneum raised at Coimbatore shows differences among themselves similar to those obtaining between the two groups, it is considered that the Sunnabile varieties are also traceable to the same wild species.

Dr. Barber describes a method for building up an ideal cane for each variety and group. The results have been reduced to curves, which show the differences sufficiently well, but involve considerable labour, as in some cases they are based on as many as

No. 2601, VOL. IO4] 
I0,000 individual measurements. He has recently dissected some fifty stools, representing twenty-four varieties, and finds overwhelming evidence that the late canes are the thickest, thus reversing earlier conclusions drawn from the behaviour of the Punjab canes late in the season.

\section{GENERAL PHYSIOLOGY.}

INCRE.ASEI) specialisation brings with it further subdivision of the sciences, and most of the new journals which are founded are restricted to narrower fields than those of existing publications. Now and then, however, an attempt is made to counteract the evils of specialisation by insistence on broad principles and by the provision of a meeting-place for workers in various branches of the same or of kindred subjects. Some such considerations must have led to the recent foundation of the Journal. of General Physiology, which is edited by Prof. Jacques Loeb, a physiologist, and Prof. W. J. V. Osterhout, a botanist, and published by the Rockefeller Institute of Medical Research. This journal, which was referred to in our issue of October 3 I last, is "devoted to the explanation of life-phenomena on the basis of the physical and chemical constitution of living matter," and first appeared in September last. Its scope may, to some extent, be illustrated by a number of reprints which we have received; they are of papers by Prof. Loeb, some physico-chemical, some botanical in nature.

In three papers on amphoteric colloids, which have appeared in the first three numbers of the new journal, Prof. Loeb has continued work previously published by him in the Journal of Biological Chemistry. Contrary to what is generally stated in the literature of colloid chemistry, he concludes that the physical properties of gelatin near the point of neutrality are affected only by the cations of a neutral salt, and not by its anions. "The error into which the colloid chemists have fallen is due to the fact that they alwavs investigated the effect of a neutral salt on a protein in the presence of the salt, while the writer took the precaution to wash the excess of salt away after it had time to act on the gelatin." Accordingly, a quantity of finely powdered gelatin is left for one hour in contact with a neutral salt solution of known concentration. The powder is then filtered off, and the excess of salt removed by reneated washing with water. The gelatin is liquefied by heating to $50^{\circ} \mathrm{C}$., and diluted with water to make a $\mathrm{r}$ per cent. solution. Then, for instance, the osmotic pressure of the solution is determined in a collodion bag. Treatment with salts of a bivalent metal $\left(\mathrm{MgCl}_{2}, \mathrm{CaCl}_{2}\right)$ does not lead to an increase of osmotic pressure, but treatment with sufficiently concentrated solutions of salts of monovalent metals ( $\mathrm{NaCl}, \mathrm{NaCNS}, \mathrm{LiNO}_{3}, \mathrm{Na}_{2} \mathrm{SO}_{4}$ ) results in an increased osmotic pressure. When the powdered gelatin is similarly treated with hydrochloric acid of varying concentrations, it is found that about $\mathrm{N} / 256 \mathrm{HCl}$ (which brings the gelatin to its isoelectric point, $\left.p_{11}=4.7\right)$ makes the total swelling, the osmotic pressure, the conductivity, and the "alcohol number" minima. On the less acid side gelatin is regarded as existing as a negative ion (e.g. gelatin- $\mathrm{H}^{-}$or gelatin$\stackrel{+}{\mathrm{Na}}$ ); on the more acid side as a cation (gelatin- $\mathrm{Cl}$ or gelatin- $\left.-\mathrm{O}^{+}\right)$.

In a later paper the author has determined the amount of bromine in combination with gelatin after treatment with hydrobromic acid of varying concentrations. He regards the curves of osmotic pressure as an "unequivocal function" of the number of gelatin NO. 260 I, VOL. IO4] bromide molecules formed. Prof. Loeb has evidently not seen the recent very careful and elaborate investigation, by Sörensen and his collaborators, of egg-albumin, in the Comptes rendus of the Carlsberg laboratory. A considerable section of this monograph deals theoretically and practically with the osmotic pressure of an amphoteric colloid of great purity in the presence of electrolytes, and takes into account factors which are not dealt with by Prof. Loeb's simple procedure. It will be interesting to see whether, after a perusal of Sörensen's monograph, Prof. Loeb still maintains his somewhat sweeping criticism of colloid chemists.

The botanical reprints are concerned with the mechanism of regeneration in Bryophyllum calycinum. The leaves of this plant possess peculiar dormant buds in each of the notches, which buds may give rise to roots and shoots so soon as the leaf is scparated from the plant. The chemical mechanism of the process is dealt with in a paper in the Annales de l'Institut Pasteur, and is a rare example of work published in English in a French journal. In other papers in the new journal the influence of the mass of a leaf on the quantity of shoots regenerated in an isolated piece of stem is measured, and the phrsiological basis of polarity is discussed. It is suggested that an inhibitory influence of the leaf unon shootformation (as compared with root-formation) is due to inhibitory substances secreted in the leaf, and carried by the sap from the leaf towards the base of the stem.

ATHER AND MATTER: BEING REMARKS ON INERTIA, ANI) ON RADIATION, AND ON THE POSSIBLE STRLCTERE OF ATOMS. ${ }^{1}$

\section{PART I.-INERTIA.}

$W^{E}$ are each of us flying through space at nineteen miles a second, probably much more. Nothing is propelling us; we continue to move by our own inertia, simply because there is nothings to stop us. Motion is a fundamental property of matter. No piece of matter is at rest in the xether, the chances are infinite against any piece having the particular velocity zero; every bit is moving steadily at some given spered, unless acted on by unbalanced force. Then it is accelerated--changed either in speed or direction, or both.

Is a matter of fact, we, like other bodies on the earth, are acted on by two slight, unbalanced forces-one which makes us revolve round the earth once a day, like a satellite; the other which makes us revolve round the sun once-a year, like a planer or asteroid. Our annual revolution is not because we are attached to the earth; we are not attached, but revolve as independent bodies, and would revolve in just the same time and way if the earth were suddenly obliterated; only then we should find the diurnal revolution transmuted into a twenty-four-hour rotation round our own centres of gravity, and the eccentricity of our annual orbit very slightly changed. In any case, there is no propelling force, only a residual radial force produclng curvature of path.

A railway train, or a ship moving steadily, is likewise subject to no resultant force. Propulsion and resistance balance. The whole nower of an engine, after the start, is spent in overcoming friction. The motion continues solely by inertia. Any steadily moving body is an example of the first law of motion. You need not try to think of a body under no force 1 Amplified from a discourse delivered at the Royal Institution on Friday, February 28, 1919, by Sir Oliver J. Lodge, F.R.S. 